\title{
Emergence of a novel subclade of influenza A(H3N2) virus in London, December 2016 to January 2017
}

\author{
H Harvala ${ }^{12}$, D Frampton ${ }^{2}$, P Grant ${ }^{1}$, J Raffle ${ }^{2}$, RB Ferns ${ }^{23}$, Z Kozlakidis ${ }^{2}$, P Kellam 4 , D Pillay ${ }^{2}$, A Hayward 5 , E Nastouli ${ }^{136}$, \\ For the ICONIC Consortium 7 \\ 1. Department of Clinical Virology, University College London Hospitals NHS Foundation Trust, London, United Kingdom \\ 2. Department of Infection and Immunity, University College of London, London, United Kingdom \\ 3. NIHR UCLH/UCL Biomedical Research Centre, London, United Kingdom \\ 4. Department of Medicine, Imperial College Faculty of Medicine, London, United Kingdom \\ 5. Department of Infectious Disease Informatics, Farr Institute of Health Informatics Research, London, United Kingdom \\ 6. Department of Population, Policy and Practice, UCL GOS Institute of Child Health, London, United Kingdom \\ 7. The members of these networks are listed at the end of the article
}

Correspondence: Eleni Nastouli (e.nastouli@ucl.ac.uk), Heli Harvala (heli.harvala@uclh.nhs.uk)

Citation style for this article:

Harvala H, Frampton D, Grant P, Raffle J, Ferns RB, Kozlakidis Z, Kellam P, Pillay D, Hayward A, Nastouli E, For the ICONIC Consortium. Emergence of a novel subclade of influenza $A\left(\mathrm{H}_{3} \mathrm{~N}_{2}\right)$ virus in London, December 2016 to January 2017. Euro Surveill. 2017;22(8):pii=30466. DOI: http://dx.doi.org/10.2807/1560-7917.

ES.2017.22.8.30466

We report the molecular investigations of a large influenza $\mathrm{A}\left(\mathrm{H}_{3} \mathrm{~N}_{2}\right)$ outbreak, in a season characterised by sharp increase in influenza admissions since December 2016. Analysis of haemagglutinin (HA) sequences demonstrated co-circulation of multiple clades ( 3 C.3a, ${ }_{3} \mathrm{C} .2 \mathrm{a}$ and $\left.{ }_{3} \mathrm{C} .2 \mathrm{a} 1\right)$. Most variants fell into a novel subclade (proposed as 3 C.2a2); they possessed four unique amino acid substitutions in the HA protein and loss of a potential glycosylation site. These changes potentially modify the $\mathrm{H}_{3} \mathrm{~N}_{2}$ strain antigenicity.

The ongoing influenza season started early in eleven European Union countries, including England, on week 46 of 2016 [1]. The majority of reported infections have been caused by clade 3 C.2a or 3 C.2a1 influenza $\mathrm{A}\left(\mathrm{H}_{3} \mathrm{~N}_{2}\right)$ viruses. The clade $3 \mathrm{C} .2 \mathrm{a}$ contains the current vaccine strain $\mathrm{A} /$ Hong Kong/4801/2014, and the first few viruses within the more recently emerged subclade 3C.2a1 were earlier shown to be antigenically matched with the vaccine component [2]. However, evidence for suboptimal vaccine effectiveness (VE) against laboratory-confirmed influenza A infection in people over 65 years-old was obtained in the first studies from Finland [3] and Sweden [4].

An outbreak of influenza $A\left(\mathrm{H}_{3} \mathrm{~N}_{2}\right)$ was first notified in our London centre on 30 December 2016. The outbreak coincided with unusually high ongoing circulation of respiratory syncytial virus (RSV) (Figure 1), and affected both patients and staff in the acute medical unit (AMU).

While infection control precautions were intensified, it resulted in multiple bay closures. We suspected that the sharp increase in the number of influenza $\mathrm{A}\left(\mathrm{H}_{3} \mathrm{~N}_{2}\right)$ infections may have been caused by the emergence of a new genetic variant of $\mathrm{H}_{3} \mathrm{~N}_{2}$, a hypothesis investigated through next generation sequencing (NGS) of influenza $\mathrm{A}\left(\mathrm{H}_{3} \mathrm{~N}_{2}\right)$ strains.

\section{Collection and analysis of respiratory samples}

The main study was based on respiratory samples $(n=1,690)$ analysed at the Department of Virology, University College of London Hospital (UCLH), United Kingdom between 21 December 2016 and 24 January 2017. Most samples were collected as part of routine diagnostics from inpatients and patients seen at the Accident and Emergency department, and to a lesser extent from outpatients. The basic epidemiological data including patients' age, admission and sampling dates as well as data on intensive care unit (ICU) admissions and deaths were collected. For comparison, results from influenza $A$ and other virus testing from UCLH since 19 September 2016 were also analysed. The study was approved by the NRES Committee London, Surrey Borders HRA, (REC reference: 13/LO/1303).

All samples were initially screened for influenza A virus by reverse transcription-PCR targeting the matrix gene. A total of 67 influenza $A\left(\mathrm{H}_{3} \mathrm{~N}_{2}\right)$ virus-positive samples obtained between 8 December 2016 and 3 January 2017 were sequenced. RNA was amplified using a modified eight-segment method [5]. Library preparations were generated as previously described $[5,6]$. A neighbour joining phylogenetic tree was constructed using Molecular Evolutionary Genetics Analysis (MEGA) 6 software [7]. Some sequences in the phylogenetic analysis were from the Global Initiative on Sharing All Influenza Data (GISAID); the authors gratefully acknowledge the 36 originating and submitting laboratories 
Percentage of positive respiratory samples for given viruses, and total number of respiratory samples tested per week, at the Department of Clinical Virology, University College of London Hospital, 19 September 2016-30 January 2017 (n=1,690 samples)

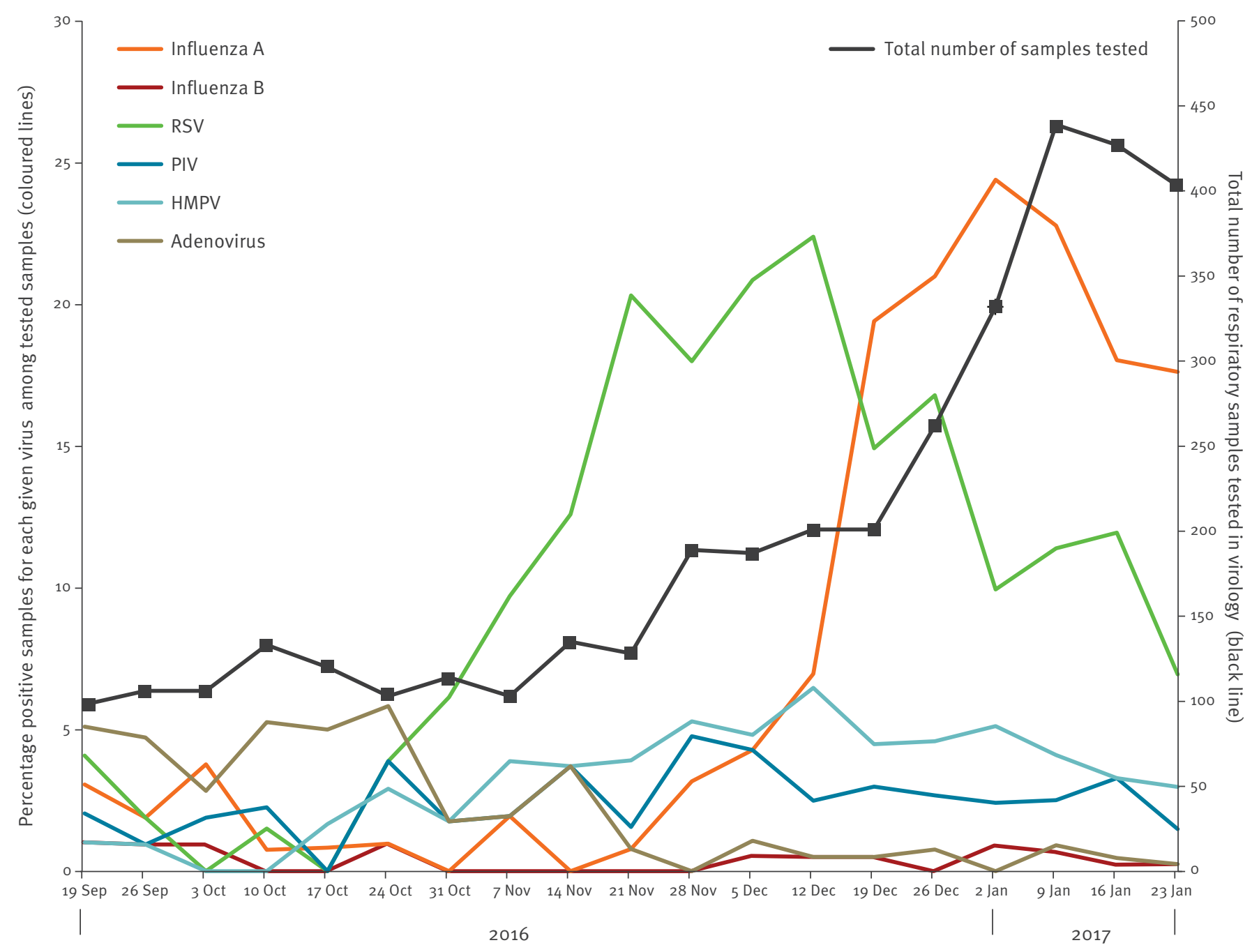

Adeno: adenovirus; HMPV: human metapneumovirus; PIV: parainfluenza virus; RSV: respiratory syncytial virus.

who contributed sequences to GISAID (www.gisaid. org).

\section{Characteristics of the influenza $\mathrm{A}(\mathrm{H} 3 \mathrm{~N} 2)$ outbreak}

Of the 1,690 respiratory samples obtained between 21 December 2016 and 24 January 2017, 352 samples were positive for influenza $A\left(\mathrm{H}_{3} \mathrm{~N}_{2}\right)$ virus (21\%; Figure 1). Of those, 294 influenza $A\left(\mathrm{H}_{3} \mathrm{~N}_{2}\right)$-positive samples had been obtained from $253 \mathrm{UCLH}$ patients. Of patients with influenza $A\left(\mathrm{H}_{3} \mathrm{~N}_{2}\right)$ infection, over $50 \%(128 / 253)$ required hospital admission. An average of three inpatients (either existing inpatients or new admissions) were identified as influenza $\mathrm{A}\left(\mathrm{H}_{3} \mathrm{~N}_{2}\right)$-positive each day, and the highest number of hospital admissions was recorded on 10 January $(n=11$; Figure $2 a)$. Over the outbreak period, six patients required ICU admission and five died. Over a third of influenza $A\left(\mathrm{H}_{3} \mathrm{~N}_{2}\right)$ infections were seen in adults over 65 years-old (99/253;
$39 \%)$, most of them admitted to hospital (72/99; $73 \%$, Figure $2 b$ ).

\section{Description of influenza $A(H 3 N 2)$ viruses circulating in London}

Phylogenetic analyses of haemagglutinin (HA) sequences indicated co-circulation of variants from subclades of 3 C.3a $(n=2), 3 C .2 a 1(n=31)$ and 3 C.2a $(n=34)$ (Figure 3).

Interestingly, our 3 C.2a virus strains differed from the previously characterised subclade $3 \mathrm{C} .2 \mathrm{a}$ strains as well as from subclade ${ }_{3}$ C.2a1, and hence we have proposed them as a new subclade 3 C.2a2. This subclade in turn split into two well defined but internally homogenous sub-clusters (cluster I and II; Figure 3), and also included all suspected outbreak cases admitted to AMU between 27 December 2016 and 3 January 2017 $(n=15)$. 


\section{FIGURE 2}

Number (A) and age distribution (B) of influenza A(H3N2)-positive patients diagnosed at the University College of London Hospitals, 16 December 2016-24 January 2017 ( $\mathrm{n}=253$ patients)

A.

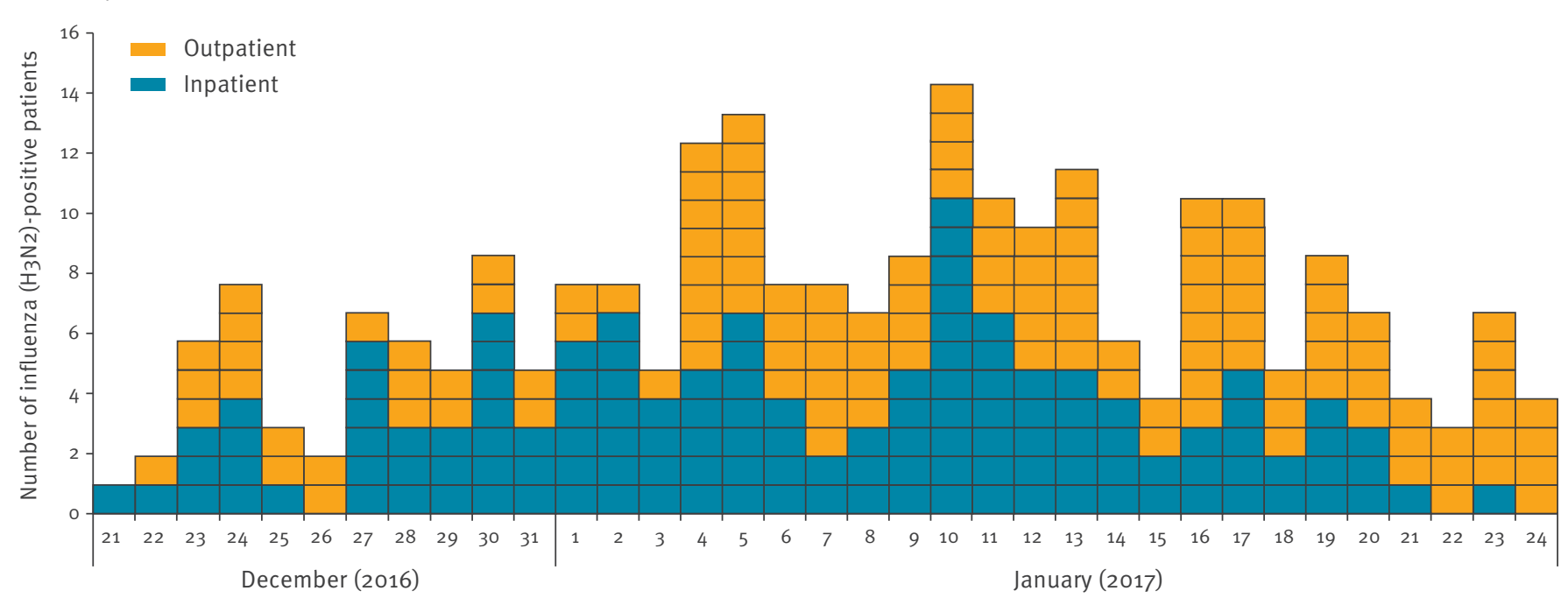

B.



Individual clades of influenza A are typically defined by amino acid substitutions that occur as they diversify from parental strains. Such substitutions are potentially functionally relevant as they may influence the antigenicity and susceptibility to neutralising antibody induced by infection with other lineages of $\mathrm{H}_{3} \mathrm{~N}_{2}$. Thus, investigated variants within the subclades $3 \mathrm{C} .2 \mathrm{a}$ and 3 C.2a1 $(n=65)$ inherited amino acid substitutions known to define their parental clades (Figure 4). All variants within the proposed subclade 3 C.2a2 shared two substitutions $\mathrm{N}_{121} \mathrm{~K}$ and $\mathrm{S} 144 \mathrm{~K}$, whereby $\mathrm{S} 144 \mathrm{~K}$ is an antigenic site flanking the receptor binding site (RBS). A further two additional substitutions were observed in each 3 C.2a2 cluster ( $158 \mathrm{~V}$ and $\mathrm{S} 219 \mathrm{Y}$ in cluster I and $\mathrm{N}_{122} \mathrm{D}$ and $\mathrm{S}_{26} \mathrm{~N}$ in cluster $\mathrm{II}$ ), all in the $\mathrm{HA}_{1}$ region and based on HA1 numbering. Cluster II viruses lost the potential N-linked glycosylation site (N122D).

\section{Discussion}

In our centre in London, the early start and higher intensity of the $2016 / 17$ influenza $A\left(\mathrm{H}_{3} \mathrm{~N}_{2}\right)$ virus epidemic mirrored that of the season 2014/15 where the subtype $\mathrm{H}_{3} \mathrm{~N}_{2}$ also predominated. During the 2014/15 season, most influenza $\mathrm{A}\left(\mathrm{H}_{3} \mathrm{~N}_{2}\right)$ infections in Europe were shown to be caused by antigenically drifted virus variants within the new genetic subgroup $3 \mathrm{C} .2 \mathrm{a}$ [8]. Our genetic analysis of London $\mathrm{A}\left(\mathrm{H}_{3} \mathrm{~N}_{2}\right)$ viruses demonstrates ongoing co-circulation of drifted variants from multiple subclades (3C.3a, 3C.2a1 and proposed 3 C.2a2). Four or more substitutions in two or more antibody binding sites are predicted to give an antigenically different virus [9] as in our case. Although we did not observe mutations in the seven positions suggested as being responsible for major transition clusters [10], position 144 is at the flank of the RBS, and additionally recognised as antigenic [11]. 


\section{FIGURE 3}

Phylogenetic tree of the haemagglutinin gene sequences of virus strains recovered in this study using reference viruses for the different phylogenetic influenza $\mathrm{A}(\mathrm{H} 3 \mathrm{~N} 2)$ clades $(\mathrm{n}=103$ sequences)



Bootstrap values obtained with 100 replicates are shown on some branches of the neighbour joining tree. The scale represents the percentage of nucleotide substitutions. Sequences are annotated in the following way: influenza type/geographical area of sample collection/sample number/year. For sequences previously characterised as belonging to the subclade 3 C.2a, this is indicated after the year in parentheses. London sequences retrieved in this study are indicated with coloured circles $(n=67)$, and the vaccine strain with a black circle.

The authors gratefully acknowledge the 36 originating and submitting laboratories who contributed sequences used in the phylogenetic analysis to the Global Initiative on Sharing All Influenza Data (GISAID; www.gisaid.org)*.

Although not necessarily determining major antigenic drift, the alterations of $\mathrm{N}$-linked glycosylation sites are likely to contribute to more complex conformational changes in the HA due to gain or loss of glycosylation and can thus facilitate immune escape [12]. Furthermore, any amino acid changes in the 140-146 region of $\mathrm{HA}$ have been shown to be characteristic for antigenically distinct viruses of epidemic significance $[9,13,14]$. The amino acid substitution S144K in the emerging subclade $3 \mathrm{C} .2 \mathrm{a} 2$ viruses together with the loss of an $\mathrm{N}$-linked glycosylation site (N122D) shows potential for antigenic drift that warrants further monitoring during this ongoing season. A limitation of our study was the lack of detailed vaccination data.
Our findings in London of the rapid emergence of genetically drifted influenza $\mathrm{A}\left(\mathrm{H}_{3} \mathrm{~N}_{2}\right)$ viruses underscore the potential for such strains to spread rapidly in hospital environments among patients and staff. Characterising emerging strains of influenza by next generation sequencing adds to the local and national monitoring of influenza trends. Further studies are needed to investigate the antigenic effects of substitutions occurring within the newly described subclade.

\section{Addendum}

*An addendum to the article was published on 05 October 2017. 


\section{FIGURE 4}

Schematic diagram demonstrating the shared haemagglutinin (HA) amino acid changes between clades 3c, 3C.2, 3C.2a, 3C.2al and 3C.2a 2 based on HA1 and HA2 numbering
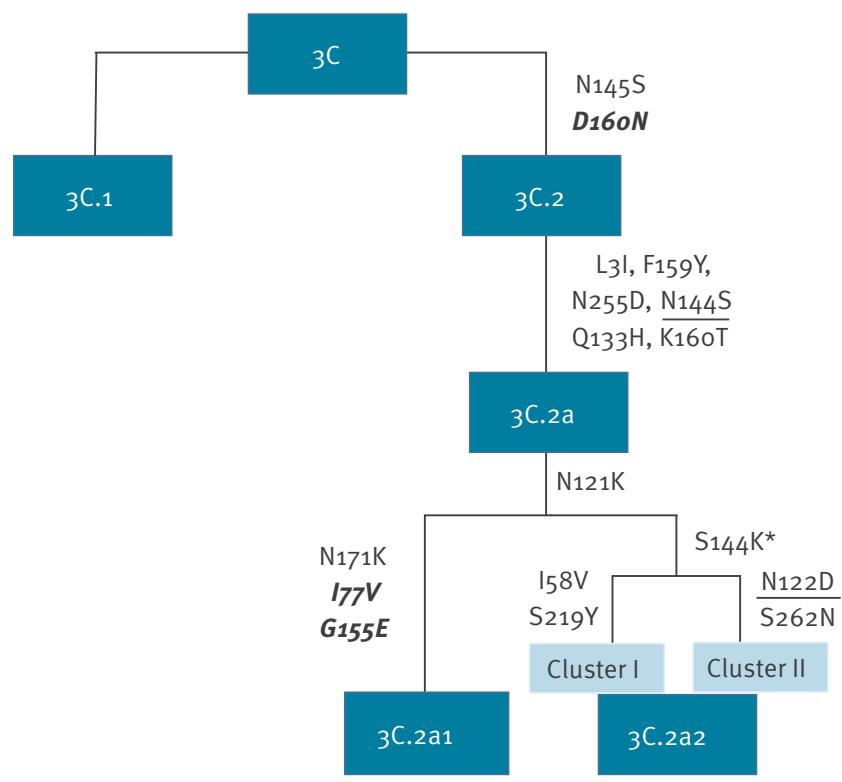

Changes in $\mathrm{HA}_{1}$ are indicated in normal font while changes in $\mathrm{HA}_{2}$ are in bold and italic. Changes in antigenic sites are shown with an asterisk $\left({ }^{*}\right)$ while changes resulting in the loss of a potential $\mathrm{N}$-linked glycosylation site are underlined.

\section{The ICONIC Consortium}

Tiziano Gallo Cassarino, Myrto Kremyda-Vlachou, Ruth Blackburn, Catherine Smith, Duncan Clark, Steven Morris, Andrew Leigh-Brown, Anne Johnson.

\section{Acknowledgements}

The authors would like to thank all the clinical, infection control and laboratory staff at UCLH and Spela Binder for the technical expertise provided with the next generation sequencing methodologies followed.

The authors gratefully acknowledge the 36 originating and submitting laboratories who contributed sequences used in the phylogenetic analysis to GISAID (www.gisaid.org).

Funding: RBF and EN receive funding from the UCLH/UCL NIHR Biomedical Research Centre and the NIHR Health Informatics Collaborative grant.

This publication presents independent research supported in part by the Health Innovation Challenge Fund T5-344 (Infection response through virus genomics - ICONIC), a parallel funding partnership between the Department of Health and Wellcome Trust.

The views expressed in this publication are those of the author(s) and not necessarily those of the Department of Health or Wellcome Trust.
Conflict of interest

None declared.

Authors' contributions

Dr Heli Harvala, wrote the manuscript and contributed to the analysis of the sequencing data. Dr Dan Frampton and Dr Paul Grant did the bioinformatics analysis. Jade Raffle and Dr Ruth Bridget Ferns performed the next generation sequencing experiments in the laboratory. Dr Zisis Kozlakidis coordinates the whole genome sequencing pipeline for ICONIC. Professor Paul Kellam, Professor Deenan Pillay and Professor Andrew Hayward analysed data and contributed to writing. Dr Eleni Nastouli designed the study, analysed data and co-wrote the manuscript. All ICONIC Consortium co-authors contributed constructively in the writing of the manuscript and offered valuable advice for the discussion part of the manuscript.

\section{References}

1. European Centre for Disease Prevention and Control (ECDC). Risk assessment of seasonal influenza, EU/EEA, 2016-2017Update, 25 January 2017. Stockholm: ECDC; 2017.

2. European Centre for Disease Prevention and Control (ECDC). Influenza virus characterisation, summary Europe, September 2016. Stockholm: ECDC; 2016.

3. National Institute for Health and Welfare. Finland. Influenssa leviää nyt - rokotuksen ehtii ottaa vielä. Helsinki: THL; 2017. Finnish. [Accessed 3 Feb 2017]. Available from: https://www.thl.fi/en/web/infektiotaudit/-/ influenssa-leviaa-nyt-rokotuksen-ehtii-ottaa-viela

4. Säsongsstatistik för influensa 2016/2017. Stockholm: Stockholm Smittskydd; 2017 [Accessed 3 Feb 2017]. Swedish. Available from: http://www.vardgivarguiden.se/ globalassets/behandlingsstod/smittskydd/statistik/influensa/ influensasasongen-2016-2017.pdf

5. Watson SJ, Welkers MR, Depledge DP, Coulter E, Breuer JM, de Jong MD, et al. Viral population analysis and minority-variant detection using short read next-generation sequencing. Philos Trans R Soc Lond B Biol Sci. 2013;368(1614):20120205. DOI: 10.1098/rstb.2012.0205 PMID: 23382427

6. Hunt M, Gall A, Ong SH, Brener J, Ferns B, Goulder P, et al. IVA: accurate de novo assembly of RNA virus genomes. Bioinformatics. 2015;31(14):2374-6. DOI: 10.1093/ bioinformatics/btv120 PMID: 25725497

7. Tamura K, Stecher G, Peterson D, Filipski A, Kumar S. MEGA6: Molecular Evolutionary Genetics Analysis version 6.0.Mol Bio Evol. 2013;30(12):2725-9. DOI: 10.1093/molbev/mst197 PMID: 24132122

8. European Centre for Disease Prevention and Control (ECDC). Influenza virus characterisation, summary Europe, May2015. Stockholm: ECDC; 2015. Available from: http://ecdc.europa.eu/ en/publications/Publications/influenza-virus-characterisationapril-2015.pdf

9. Wiley DC, Wilson IA, Skehel JJ. Structural identification of the antibody-binding sites of Hong Kong influenza haemagglutinin and their involvement in antigenic variation. Nature. 1981;289(5796):373-8. DOI: 10.1038/289373ao PMID: 6162101

10. Koel BF, Burke DF, Bestebroer TM, van der Vliet S, Zondag GC, Vervaet G, et al. Substitutions near the receptor binding site determine major antigenic change during influenza virus evolution. Science. 2013;342(6161):976-9. DOl: 10.1126/ science.1244730 PMID: 24264991

11. Yang H, Carney PJ, Chang JC, Guo Z, Villanueva JM, Stevens J. Structure and receptor binding preferences of recombinant human $\mathrm{A}\left(\mathrm{H}_{3} \mathrm{~N}_{2}\right)$ virus hemagglutinins.Virology. 2015;477:18-31. DOI: 10.1016/j.virol.2014.12.024 PMID: 25617824

12. Wilson IA, Cox NJ. Structural basis of immune recognition of influenza virus hemagglutinin. Annu Rev Immunol. 1990;8(1):737-71. DOI: 10.1146/annurev.iy.08.040190.003513 PMID: 2188678

13. Kobayashi Y, Suzuki Y. Evidence for N-glycan shielding of antigenic sites during evolution of human influenza $A$ virus hemagglutinin.J Virol. 2012;86(7):3446-51. DOI: 10.1128/ JVI.06147-11 PMID: 22258255

14. Stucker KM, Schobel SA, Olsen RJ, Hodges HL, Lin X, Halpin $\mathrm{RA}$, et al. Haemagglutinin mutations and glycosylation changes shaped the $2012 / 13$ influenza $A\left(H_{3} N_{2}\right)$ epidemic, 
Houston, Texas. Euro Surveill. 2015;20(18):21122. DOI:

10.2807/1560-7917.ES2015.20.18.21122 PMID: 25990233

\section{License and copyright}

This is an open-access article distributed under the terms of the Creative Commons Attribution (CC BY 4.0) Licence. You may share and adapt the material, but must give appropriate credit to the source, provide a link to the licence, and indicate if changes were made.

This article is copyright of the authors, 2017. 